Check for updates

Cite this: RSC Adv., 2017, 7, 35565

Received 1st June 2017

Accepted 4th July 2017

DOI: $10.1039 / c 7 r a 06102 a$

rsc.li/rsc-advances

\section{Anchovy-derived nitrogen and sulfur co-doped porous carbon materials for high-performance supercapacitors and dye-sensitized solar cells $\uparrow$}

\begin{abstract}
Chang Ki Kim, In Taek Choi, (D) Sung Ho Kang and Hwan Kyu Kim (DD*
Anchovies are a popular food worldwide, but a large amount of the anchovy is discarded as food waste in Korea, after cooking for anchovy juices. In order to reduce and reuse the food waste of anchovies, anchovyderived nitrogen and sulfur co-doped porous carbons (AnCs) were prepared by a simple carbonization and alkali activation method for use as superior electrodes in supercapacitors and dye-sensitized solar cells (DSSCs). AnCs with a high specific surface area and moderate heteroatom ( $N$ and $\mathrm{S}$ ) doping levels enabled both applications. The chemical composition and porosity of AnC materials were characterized by X-ray photoelectron spectroscopy (XPS) and nitrogen sorption isotherm measurements, exhibiting high nitrogen and sulfur contents (2.09 and 0.81 atom\%, respectively) and specific surface area (2622 $\mathrm{m}^{2}$ $\mathrm{g}^{-1}$ ). When used as a supercapacitor electrode, the AnC-900-2.0 sample exhibited superior specific capacitance of $613 \mathrm{~F} \mathrm{~g}^{-1}$ in $6 \mathrm{M} \mathrm{KOH}$ electrolyte at a current density of $1 \mathrm{~A} \mathrm{~g}^{-1}$ and good long-term stability. Moreover, the electrocatalytic activities of AnCs were investigated with a symmetrical dummy cell by using two identical electrodes through electrochemical impedance spectroscopy (EIS). The AnC as a counter electrode (CE) for DSSCs exhibited much better electrocatalytic performance than a Pt CE toward the $\mathrm{Co}(\mathrm{bpy})_{3}{ }^{2+/ 3+}$ redox couple. An AnC-900-2.0-based DSSC employing a SM-315 porphyrin as a superior organic sensitizer led to a power conversion efficiency (PCE) of $12.72 \%$, which is to the best of our knowledge the highest value reported for DSSCs based on carbon nanomaterials as CEs, compared to Pt-CE (12.23\%), due to an enhanced fill factor caused by its better electrocatalytic ability. The superior specific capacitance and excellent photovoltaic performance could be due to high specific surface area and moderate heteroatom doping level.
\end{abstract}

\section{Introduction}

In recent decades, because of the depletion of fossil fuels, environmental problems and rapid population increase, development of renewable energy and energy storage devices for efficient energy production have attracted much attention. ${ }^{1,2}$ Supercapacitors and DSSCs are one of the most promising energy storage and conversion devices, and many researchers are working to improve their performance. In both applications, the electrodes are key components in determining the overall performance, so the development of efficient electrodes is needed. For electrode materials, nanostructured carbon materials, such as activated carbons (ACs), ${ }^{3,4}$ carbon nanotubes (CNTs), ${ }^{5}$ graphene ${ }^{6,7}$ and ordered mesoporous carbons (OMCs) ${ }^{8}$ are widely used in energy storage and conversion devices such

Global GET-Future Laboratory, Department of Advanced Materials Chemistry, Korea University, 2511 Sejong-ro, Sejong 339-700, Korea.E-mail: hkk777@korea.ac.kr

$\dagger$ Electronic supplementary information (ESI) available: Detailed experimental section, electrochemical measurements and characterisation data, such as XRD, cyclic voltammogram, Nyquist plots, and electrochemical stability. See DOI: 10.1039/c7ra06102a as supercapacitors, ${ }^{9-11}$ lithium ion batteries, ${ }^{12}$ fuel cells ${ }^{13}$ and $\operatorname{DSSCs}^{14,15}$ due to their various foams and outstanding thermal, mechanical, electrical and electrochemical properties.

Supercapacitors (also known as ultracapacitors or electrochemical capacitors) are promising energy storage devices due to excellent cycle stability, high power density, good chemical stability and rapid charge-discharge rate. Based on their different charge mechanisms, supercapacitors consist of electric double layer capacitors (EDLCs) and pseudocapacitors. EDLCs store the charge electrostatically by reversible adsorption of ions at the interface between electrode and electrolyte (non-faradaic process). On the other hand, pseudocapacitors store the charge electrochemically by reversible redox reaction (faradaic process). ${ }^{3,16-18}$ In EDLCs, porous carbon materials, including activated carbons, ordered mesoporous carbons, graphenes and carbon nanotubes have been widely used as electrode material owing to their good conductivity, high specific surface area, chemical stability and low cost. Unfortunately, porous carbon materials have low energy density owing to their limited capacitance. Therefore, today's research has focused on further enhancing the capacitance of carbon materials. 
Since being first developed two decades ago by O'Regan and Grätzel, DSSCs have been one of the most promising photovoltaic devices among other thin film photovoltaic systems due to their ease of fabrication, high power conversion efficiency (PCE), environmentally friendly nature and low cost. ${ }^{\mathbf{1 4 , 1 5 , 1 9}}$ DSSCs consist of three important components: dye-coated $\mathrm{TiO}_{2}$ film, counter electrode (CE) and electrolyte. In these important components, the CE serves as an electrocatalyst to catalyse the reduction of the redox couple in the electrolyte. Platinum (Pt) is most commonly used as CE because of its excellent electrocatalytic activity. However, because of its high cost, low abundance in nature and electrochemical instability, using Pt as a CE has major drawbacks for large scale production of DSSCs. Finding CE materials with low cost, high stability and high electrocatalytic activity for replacing Pt is an important challenge. ${ }^{\mathbf{2 0 - 2 5}}$ In this regard, carbon-based materials have been the second most widely studied materials as alternatives to Pt CEs in DSSCs because of their good electrocatalytic activity, electrochemical stability and low cost. ${ }^{7,20,22,23,25}$

Recently, heteroatom (e.g., nitrogen, boron, sulfur, and phosphorus)-doped porous carbon materials have been used as electrode materials of supercapacitors and DSSCs. ${ }^{26-29}$ Introducing heteroatoms into the carbon framework can increase the wettability, and add to pseudocapacitance and electrocatalytic activity. One particularly promising development has been the recent establishment of the high electrocatalytic performance of nitrogen (N)-enriched carbon nanomaterials. The electrocatalytic properties of these systems are typically attributed to high charge polarisation arising from the difference in electronegativity between carbon $(\chi=2.55)$ and nitrogen $(\chi=3.04)$, leading to enhanced charge-transfer capability and thus increased catalytic activity. Furthermore, comparing with single doping, multiple doping is a versatile synthetic approach, which can further tune the properties of mono-doped carbon nanomaterials. Usually, nitrogen doping is preferential in tuning the electronic properties of the carbon material, whereas sulfur, due to its larger size, has been used for applications where its easily polarisable electron pairs and thus higher chemical reactivity are of interest. ${ }^{28,30}$

Currently, two major strategies have been used for the preparation of heteroatom-doped carbon materials. In the first strategy, a mono-heteroatom is introduced by treating carbon materials in the presence of a heteroatom-rich agent, such as ammonia, melamine, urea, benzyl disulfide and sulfonated polystyrene at high temperatures. ${ }^{31-34}$ The co-doping strategy is to carbonise heteroatom-containing precursors including: both melamine and benzyl disulfide; thiourea; both pyrimidine and thiophene; bacteria; both PVP and sulfonated polystyrene; and ammonium thiocyanate. ${ }^{3-39}$ The other strategy for monoheteroatom doping is to carbonise heteroatom-containing precursors directly, including polypyrrole, polyacrylonitrile and polyaniline. ${ }^{\mathbf{4 0 - 4 2}}$ However, the above strategies are highly dependent on petrochemical sources. Their applicability is limited by the decreasing availability of fossil fuels. Therefore, it is necessary to produce heteroatom-doped carbon materials using environmentally friendly resources, and reducing the use of fossil fuels. In recent years, some research has shown the preparation of heteroatom-doped carbon materials by using biomass resources, such as human hair, foods and animal products (such as animal bones and skins). ${ }^{30,43-47}$ Anchovy is a popular fish food worldwide because of its abundant calcium, iron and omega- 3 content, but a large amount of the anchovy was discarded as food waste in Korea, after cooking for anchovy juices. The anchovy contains carbonaceous materials, such as proteins and lipids, which make it a promising nitrogen-rich precursor of carbon materials; ${ }^{48}$ it also contains taurine as a sulfur source. Herein, we demonstrate the synthesis of anchovy-derived nitrogen and sulfur co-doped porous carbon materials using carbonization and activation of an anchovy precursor for high-performance supercapacitor and DSSC devices, taking advantage of the high charge polarisation of the nitrogen atom and large size of the sulfur atom. To our knowledge, the application of nitrogen and sulfur co-doped porous carbon materials for both supercapacitors and DSSCs has not so far been reported.

\section{Experimental section}

\subsection{Preparation of materials}

Anchovy-derived nitrogen and sulfur co-doped porous carbons (AnCs) were prepared by a simple carbonization and alkali activation method. Typically, a three-step strategy was used to prepare the activated carbon. Firstly, a dried anchovy powder (purchased from a local Jochiwon market, Sejong, Korea) was transferred into a quartz tubular furnace and heated at $300{ }^{\circ} \mathrm{C}$ for $1 \mathrm{~h}$ under $\mathrm{N}_{2}$ atmosphere for pre-carbonization (at a ramp of $5{ }^{\circ} \mathrm{C} \min ^{-1}$ ). The following step was an activation and carbonization process: the pre-carbonized material was mixed with various mass ratios of $\mathrm{KOH}(\mathrm{KOH} /$ pre-carbonized material: 0.5, $1.0,2.0)$ and then directly heated at a specific temperature (700, $800,900{ }^{\circ} \mathrm{C}$ ) for $2 \mathrm{~h}$ under $\mathrm{N}_{2}$ atmosphere (at a ramp of $5{ }^{\circ} \mathrm{C}$ $\min ^{-1}$ ). The final step was the washing process for removing the potassium compounds and any impurities. The anchovyderived activated carbon obtained was washed several times with $2 \mathrm{M} \mathrm{HCl}$ and deionised water. After filtration, the samples were dried at $70{ }^{\circ} \mathrm{C}$ in an electric vacuum oven. The prepared samples were denoted as AnC-XXX-Y (where AnC is the anchovyderived nitrogen and sulfur co-doped porous carbon, $X X X$ is the carbonization temperature and $Y$ is the ratio of weight $\mathrm{KOH}_{\mathrm{HO}} /$ weight carbon$)$.

\subsection{Characterization}

The surface morphology of the prepared samples was observed by field-emission scanning electron microscopy (FESEM) using an S-4700 (Hitachi, Japan) microscope operated at an acceleration voltage of $10 \mathrm{kV}$. The transmission electron microscopy (TEM) was obtained using an EM 912 Omega at $120 \mathrm{kV}$. X-ray photoelectron spectroscopy (XPS) was carried out with an AXIS-NOVA (Kratos) X-ray photoelectron spectrometer using an $\mathrm{Al}-\mathrm{K} \alpha \mathrm{X}$-ray source operated at $150 \mathrm{~W}$ under pressure of $2.6 \times$ $10^{-9}$ Torr. X-ray diffraction (XRD) was performed using a Rigaku Smartlab diffractometer with $\mathrm{CuK} \alpha$ radiation operated at $40 \mathrm{kV}$ and $30 \mathrm{~mA}$. The nitrogen sorption isotherms were measured at 
$77 \mathrm{~K}$ using a Micromeritics ASAP 2020. Specific surface areas of prepared samples were determined by nitrogen adsorption data in the relative pressure range from 0.05 to 0.2 using the Brunauer-Emmett-Teller (BET) equation. Total pore volumes were determined by the amount of gas adsorbed at relative pressure of 0.99. Pore size distributions were calculated by Micromeritics software based on density functional theory (DFT) method.

\subsection{Electrochemical measurements}

In capacitive performance measurements of AnC-based electrodes of the supercapacitor, the electrochemical performance of prepared AnCs were carried out in a three-electrode system using platinum as the counter electrode, $\mathrm{Ag} / \mathrm{AgCl}$ as the reference electrode, AnC as the working electrode and $6 \mathrm{M}$ $\mathrm{KOH}$ as the electrolyte and measured by an electrochemical workstation (VersaSTAT 3). The working electrodes were fabricated by coating a slurry containing $80 \mathrm{wt} \%$ active material, $10 \mathrm{wt} \%$ Super P and $10 \mathrm{wt} \%$ polyvinylidene fluoride (PVDF) onto nickel foam (99.8\% pure, MTI Corp.). The amount of active material was loaded about $2-3 \mathrm{mg}$ on the $\mathrm{Ni}$ foam and the $\mathrm{Ni}$ foam area was $1 \mathrm{~cm}^{2}$ (the amount of active material: $2-3 \mathrm{mg} \mathrm{cm} \mathrm{cm}^{-2}$ ). The electrochemical measurements were carried out by cyclic voltammetry (CV) and galvanostatic charge-discharge (GCD). $\mathrm{CV}$ and GCD were recorded in potential window of 0 to $-1 \mathrm{~V}$. The specific capacitance $\left(C_{\mathrm{S}}\right)$ was calculated from GCD measurements using the following equation:

$$
C_{\mathrm{S}}=\frac{I \times \Delta t}{m \times \Delta V}
$$

where $I$ is the current, $\Delta t$ the discharging time, $m$ the mass of the active material, and $\Delta V$ is the potential window.

In electrochemical measurements of AnC-based counter electrodes of DSSC, the CE was fabricated by coating prepared AnC material onto the fluorine-doped tin oxide (FTO) substrate using an electrospray technique..$^{7,20,22,23,25}$ The $\mathrm{Pt}$ reference electrode was prepared by deposition of $\mathrm{H}_{2} \mathrm{PtCl}_{6}$ solution and sintered at $400{ }^{\circ} \mathrm{C}$ for $15 \mathrm{~min}$. The preparation method of the counter electrode is described in (ESI $\dagger$ ).

\section{Results and discussion}

The preparation method of AnCs is illustrated in Fig. 1. Typically, a simple carbonization and activation method for preparation of AnCs was used in this study. Fig. 2a-c shows SEM images of a dried anchovy powder, pre-carbonized material, and AnC-900-2.0 sample, respectively. The surface morphologies of the dried anchovy powder and pre-carbonized material (Fig. 2a and b) were smooth and bulk particle. After activation and carbonization at $900{ }^{\circ} \mathrm{C}$ (AnC-900-2.0), the surface morphology became rough and with a porous structure, as shown in Fig. 2c. The porous structure of the prepared AnC-900-2.0 can also be confirmed by the TEM image (Fig. 2d). Carbons with porous structure exhibit good capacitance characteristics when used as supercapacitor electrodes due to their high specific surface area.

Fig. 3a shows the nitrogen sorption isotherm data of AnCs using different carbonization temperatures, and the porosity properties of the AnC materials are summarised in Table 1. The nitrogen isotherms of the AnC (AnC-700-2.0, AnC-800-2.0, and AnC-900-2.0) samples show a typical type IV isotherm with $\mathrm{H} 3$ hysteresis loop. ${ }^{49} \mathrm{~A}$ hysteresis loop extending from 0.4 to 1.0 was observed for AnC samples, indicating the coexistence of both micropore and mesopore structures in these materials. With a carbonization temperature increase from 700 to $900{ }^{\circ} \mathrm{C}$, BET surface area $\left(2748,2857\right.$, and $2622 \mathrm{~m}^{2} \mathrm{~g}^{-1}$ ) was almost unchanged, but total pore volume $\left(1.51,1.84\right.$, and $\left.1.95 \mathrm{~cm}^{3} \mathrm{~g}^{-1}\right)$ increased. In particular, the mesopore volume $(0.66,1.21$, and $1.51 \mathrm{~cm}^{3} \mathrm{~g}^{-1}$ ) was enhanced. Increasing the BET surface area and mesopore volume within the carbon structure allows more efficient electrolyte diffusion and charge accumulation when used as a supercapacitor electrode. The wide-angle X-ray diffraction (XRD) patterns of prepared AnCs are shown in Fig. S1b. $\dagger$ All AnCs prepared with different carbonization temperatures and $\mathrm{KOH}$ ratios demonstrate almost the same

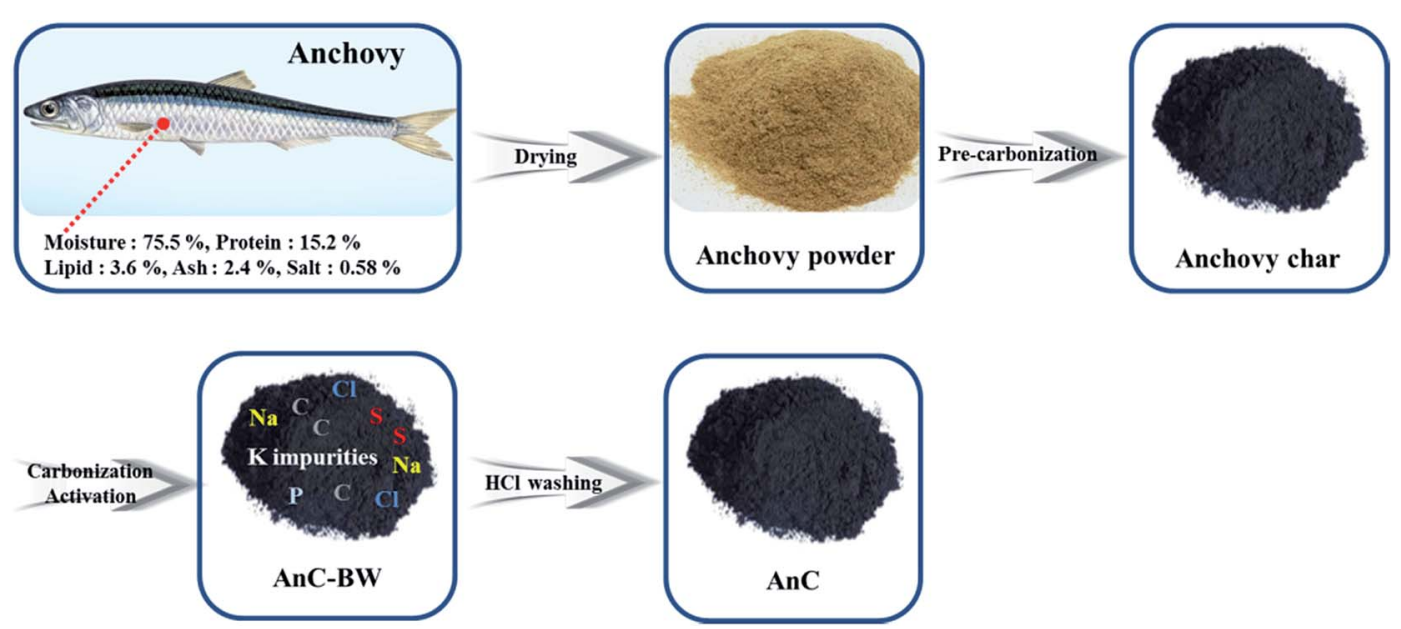

Fig. 1 Approximate composition of a dried anchovy powder and schematic illustration for the preparation of anchovy-derived nitrogen and sulfur co-doped porous carbon materials. 

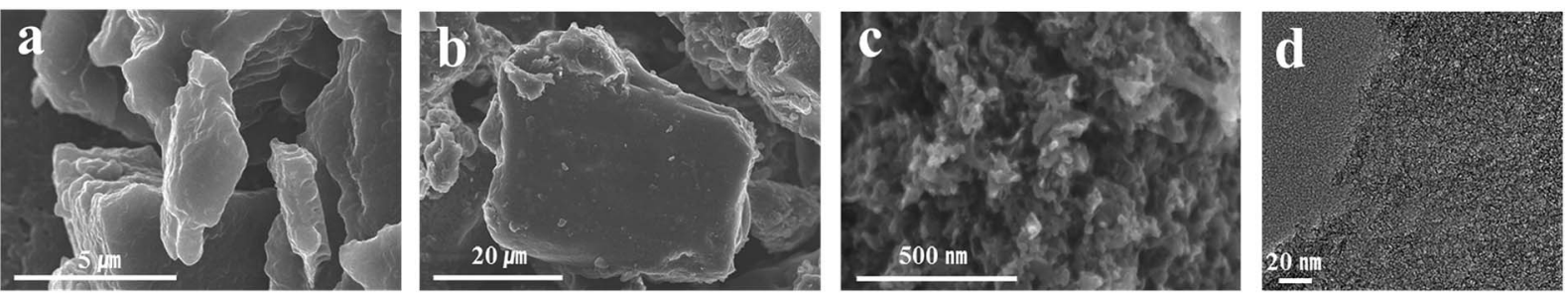

Fig. 2 (a) Scanning electron microscopy (SEM) image of a dried anchovy powder; (b) SEM image of pre-carbonized material; (c) SEM image of AnC-900-2.0 sample (d) transmission electron microscopy (TEM) image of AnC-900-2.0 sample.
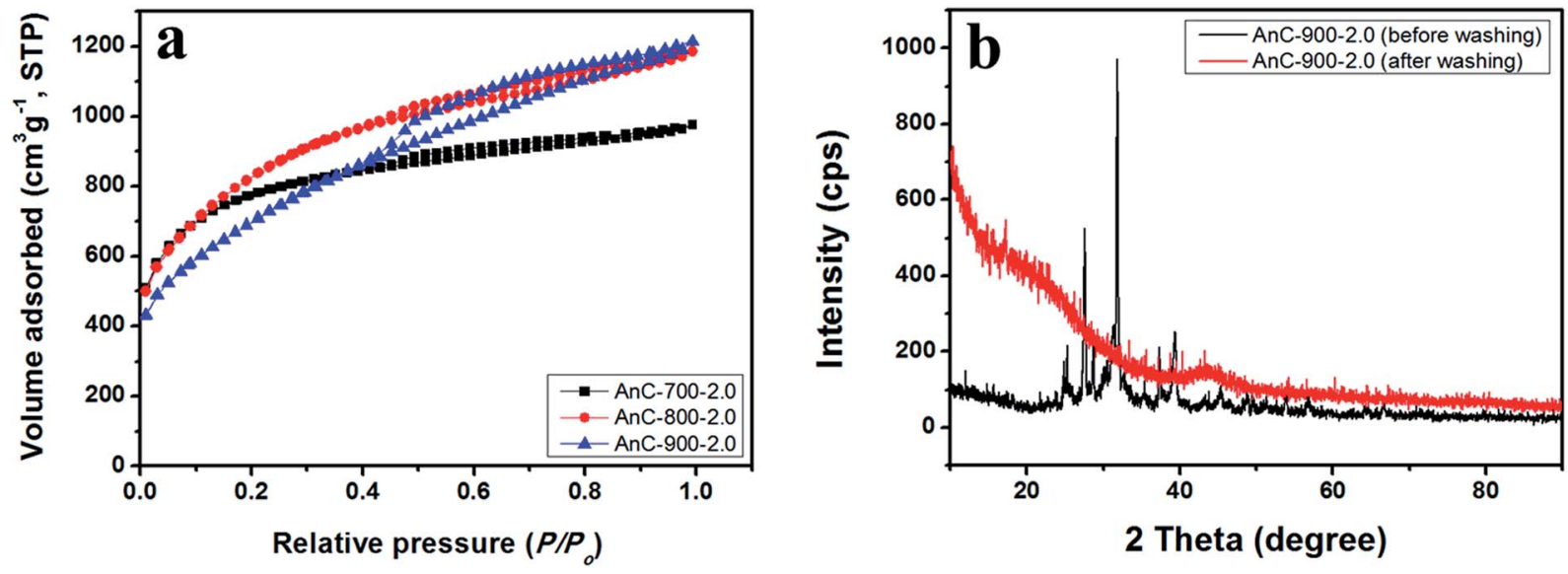

Fig. 3 (a) Nitrogen sorption isotherm data of anchovy-derived carbon materials using different carbonization temperatures (700, 800 and $900^{\circ} \mathrm{C}$ ). (b) Powder X-ray diffraction (XRD) patterns of AnC-900-2.0 sample (black line: before washing, red line: after washing).

Table 1 Porosity characteristics of anchovy-derived carbon materials ${ }^{a}$

\begin{tabular}{lllll}
\hline Samples & $S_{\text {BET }}\left(\mathrm{m}^{2} \mathrm{~g}^{-1}\right)$ & $V_{\text {total }}\left(\mathrm{cm}^{3} \mathrm{~g}^{-1}\right)$ & $V_{\text {micro }}\left(\mathrm{cm}^{3} \mathrm{~g}^{-1}\right)$ & $V_{\text {meso }}\left(\mathrm{cm}^{3} \mathrm{~g}^{-1}\right)$ \\
\hline AnC-700-2.0 & 2748 & 1.51 & 0.58 & 0.66 \\
AnC-800-2.0 & 2857 & 1.84 & 0.16 & 1.21 \\
AnC-900-2.0 & 2622 & 1.95 & 0.06 & 1.51
\end{tabular}

${ }^{a} S_{\mathrm{BET}}=\mathrm{BET}$ surface area, $V_{\text {total }}=$ total pore volume, $V_{\text {micro }}=$ micropore volume, $V_{\text {meso }}=$ mesopore volume.

curves. These materials display two typical peaks at approximately $2 \theta=21$ and $43.5^{\circ}$, corresponding to diffractions of (002) and (100), respectively, showing that all the AnCs were amorphous and disordered carbon structures. ${ }^{50}$ Fig. $3 \mathrm{~b}$ shows XRD patterns of AnC-900-2.0 sample, before and after washing ( $\mathrm{HCl}$ treatment). After washing with $2.0 \mathrm{M} \mathrm{HCl}$, no diffractions due to potassium compounds $\left(\mathrm{K}_{2} \mathrm{CO}_{3}\right.$ or $\left.\mathrm{K}_{2} \mathrm{O}\right)$ were observed, confirming the complete removal of potassium impurities by acid washing.

X-ray photoelectron spectroscopy (XPS) was performed to analyse the elemental composition of prepared AnCs (Fig. 4 and Table 2). The XPS spectra revealed the presence of carbon, oxygen, nitrogen, and sulfur atoms, as well as other elements, such as sodium, calcium, phosphorus and chlorine in precarbonized material. In contrast, the XPS spectrum of AnCs clearly showed the presence of carbon, oxygen, nitrogen, and sulfur, whereas other elements almost disappeared, probably as a result of their removal by high-temperature pyrolysis and acid treatment. As shown in Table 2, the contents of these heteroatoms (N, O and $\mathrm{S}$ ) gradually decrease with increasing carbonization temperature, but the nitrogen (2.09 atom\%) and sulfur (0.81 atom\%) content was maintained in the AnC-900-2.0 sample. In a carbon structure, these doped heteroatoms can increase the wettability, pseudocapacitance and electrocatalytic ability.

The high resolution XPS spectra of AnC-900-2.0 carbon are shown in Fig. 5. The deconvolution of $\mathrm{C}_{1 \mathrm{~s}}$ spectrum resulted in four well resolved peaks with binding energies around 284.6, 285.7, 286.8 and $288.5 \mathrm{eV}$, labeled as C1, C2, C3 and C4, respectively. ${ }^{51} \mathrm{C} 1$ peak corresponds to $\mathrm{sp}^{2}(\mathrm{C}=\mathrm{C})$ and $\mathrm{sp}^{3}(\mathrm{C}-\mathrm{C})$ hybridised graphitic carbon while $\mathrm{C} 2$ is attributed to $\mathrm{C}-\mathrm{O}$ bond of phenol, alcohol or ether and/or $\mathrm{C}=\mathrm{N}$ bond. The $\mathrm{C} 3$ peak is assigned to carbonyl or quinone groups and $\mathrm{C}-\mathrm{N}$ linkage, and C4 to carboxyl or ester linkages. High resolution XPS spectra of 


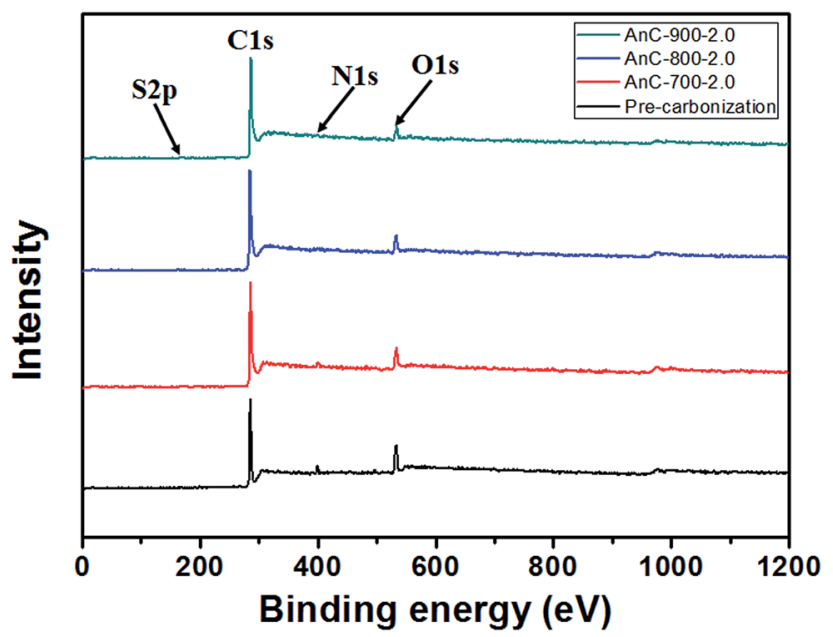

Fig. 4 X-ray photoelectron spectroscopy (XPS) patterns of precarbonized material and AnC samples.
$\mathrm{N}_{1 \mathrm{~s}}$ was deconvoluted into four different peaks with binding energies around 398.8, 400.0, 401.1, and 403.0 eV referred to as N1 (pyridinic-N), N2 (pyrrolic-N), N3 (quaternary-N), and N4 (pyridinic-N-oxide), respectively. ${ }^{51,52}$ Peak N1 and N2 atoms are located at edge or defect sites; they do not increase the number of electrons in the delocalised $\pi$-system. N3 atoms substitute for carbon atoms within the graphitic structure. Therefore, they have the same configuration as graphitic carbon atoms but they introduce extra electrons into the delocalised $\pi$-system. Pyridinic-N can also be present in its oxidised form (N4). Fig. 5c shows the high-resolution $\mathrm{O}_{1 \mathrm{~s}}$ spectra of the AnC-900-2.0 sample and their deconvolution leads to three separate peaks with binding energies around 531.3, 532.4, and $533.6 \mathrm{eV}$, labeled as $\mathrm{O} 1, \mathrm{O} 2$ and $\mathrm{O} 3$ respectively. ${ }^{53}$ Peak $\mathrm{O} 1$ is attributed to $\mathrm{C}=\mathrm{O}$ of carbonyl or ketone groups, $\mathrm{O} 2$ to carbonyl oxygen of esters, anhydrides, amides, and the oxygen atom of phenol, alcohol or ether groups, and $\mathrm{O} 3$ to oxygen of carboxylic groups. The $S_{2 p}$ spectra of AnC-900-2.0 carbon can be divided primarily

Table 2 Elemental compositions of pre-carbonized carbon and AnC samples

\begin{tabular}{|c|c|c|c|c|c|c|c|c|}
\hline Samples & C $1 \mathrm{~s}$ & $\mathrm{Ca} 2 \mathrm{p}$ & $\mathrm{Cl} 2 \mathrm{p}$ & $\mathrm{N}$ 1s & $\mathrm{Na} 1 \mathrm{~s}$ & O 1s & P 2p & S $2 p$ \\
\hline AnC-700-2.0 & 85.88 & & & 3.65 & & 9.34 & & 1.13 \\
\hline AnC-800-2.0 & 89.08 & & & 0.55 & & 9.35 & & 1.67 \\
\hline AnC-900-2.0 & 90.53 & & & 2.09 & & 6.57 & & 0.81 \\
\hline
\end{tabular}
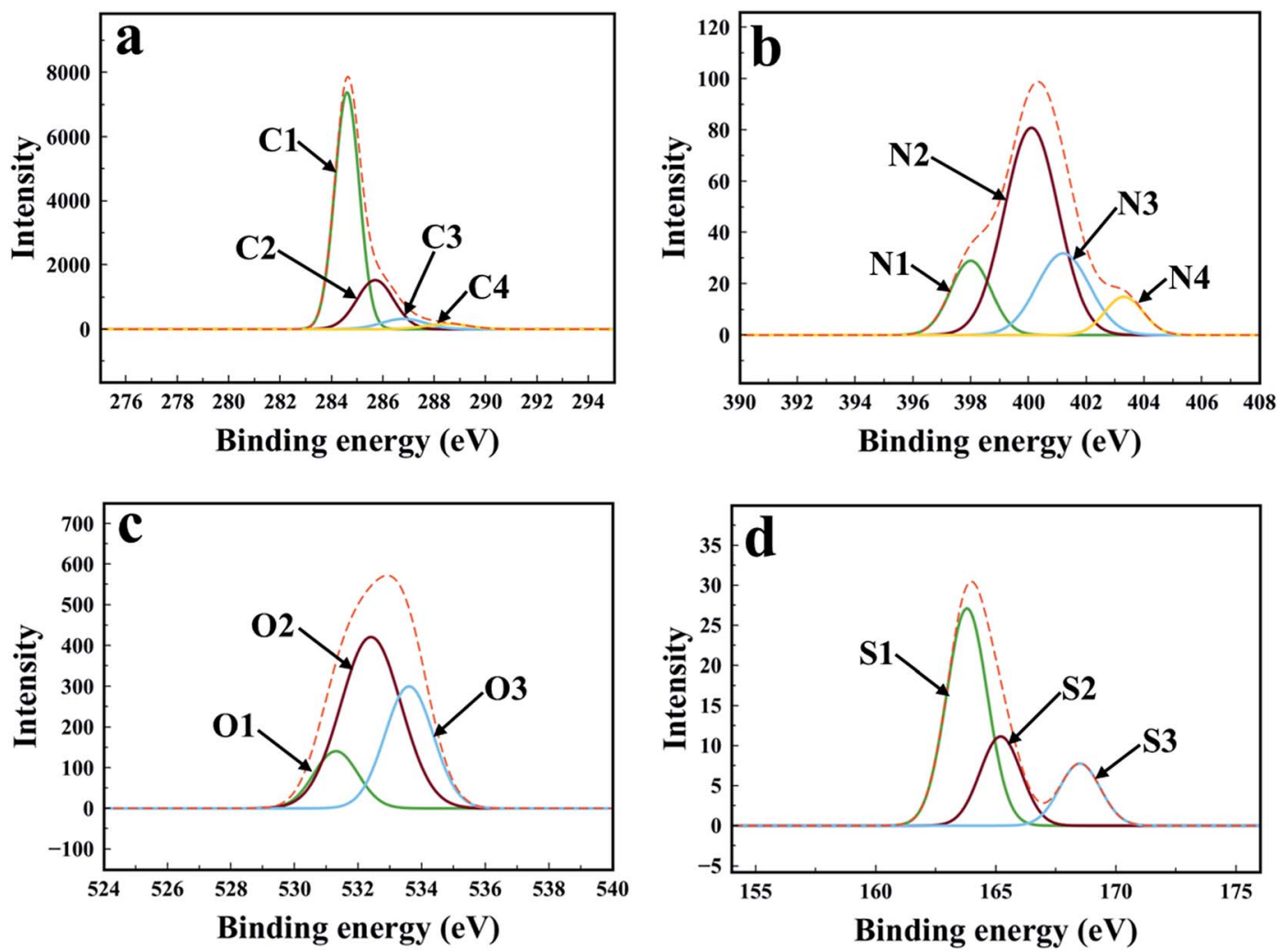

Fig. 5 High resolution XPS spectra of AnC-900-2.0 carbon material ((a): $C_{1 s,}$ (b): $N_{1 s,}$ (c): $O_{1 s,}$ and (d): $S_{2 p}$ ). 
into the following three peaks: ${ }^{54}$ the $\mathrm{S} 1$ peak $(163.8 \mathrm{eV})$ agrees with the $\mathrm{C}-\mathrm{S}-\mathrm{C}$ covalent bond of the thiophene-S, while the S2 $(165.2 \mathrm{eV})$ and $\mathrm{S} 3(168.5 \mathrm{eV})$ peaks originate from sulfoxide $(\mathrm{C}-$ $\mathrm{SO}_{2}-\mathrm{C}$ ) and sulfone $\left(\mathrm{C}-\mathrm{SO}_{3}-\mathrm{C}\right)$.

\subsection{Electrochemical properties in supercapacitors}

To evaluate the supercapacitor characteristics of prepared AnC electrodes and the effect of heteroatom doping on electrochemical performance, a three-electrode configuration was used. Fig. 6a shows the CV curves of AnC samples prepared at various carbonization temperatures $\left(700,800\right.$ and $\left.900{ }^{\circ} \mathrm{C}\right)$ at a scan rate of $100 \mathrm{mV} \mathrm{s}^{-1}$ from $-1 \mathrm{~V}$ to $0 \mathrm{~V}$. All the AnC samples exhibit typical rectangular-like shapes with some humps, which indicate coexistence of electrical double-layer capacitance and pseudocapacitance. Moreover, the CV curves of AnC samples performed at various scan rates (Fig. 6c) show that the curves maintained their rectangular shape well even at a high scan rate of $100 \mathrm{mV} \mathrm{s}^{-1}$, demonstrating the good rate performance of the samples as supercapacitor electrodes. In order to further investigate the performance of AnCs, galvanostatic charge-discharge measurements were carried out at $1 \mathrm{~A} \mathrm{~g}^{-1}$ in a three-electrode configuration (Fig. 6b). The inflections at $-0.4 \mathrm{~V}$ of AnCs imply the impact of pseudocapacitance due to the effect of the doped heteroatoms. This pseudocapacitance is caused by the redox reactions of a heteroatom-containing functional group, which can apparently improve the specific capacitance. Galvanostatic charge/discharge measurements were applied at different current densities to evaluate the capacitance performance, and the results are shown in Fig. 6d. A distinctive ideal symmetric triangular charge/discharge profile was observed, indicating the reversible adsorption/ desorption of ions.

Rate capability is an important feature for supercapacitors because the main application of a supercapacitor is to charge instantaneously and deliver energy very quickly. Therefore, to test this feature, charge-discharge measurements were carried out for all the AnC electrodes with increasing current density up to $10 \mathrm{~A} \mathrm{~g}^{-1}$. The specific capacitances of the AnC electrodes were determined by galvanostatic charge-discharge measurements according to the above-mentioned equation $\left(C_{\mathrm{s}}=I \times \Delta t\right)$ $m \times \Delta V$ ). When the current density was increased from 1 to 10 $\mathrm{A} \mathrm{g}^{-1}$, the specific capacitance of each prepared AnC decreased, due to inadequate time for electrolyte ion diffusion into the entire pore structure. However, AnC-800-2.0 and AnC-900-2.0 samples still retained over $250 \mathrm{~F} \mathrm{~g}^{-1}$ at high current density (10 A $\mathrm{g}^{-1}$ ), indicating excellent rate capability (see Fig. 7a). Furthermore, the cyclic stability of the AnC-900-2.0 electrode was evaluated in a three-electrode system by continuous charge-discharge measurement at a current density of $10 \mathrm{~A} \mathrm{~g}^{-1}$ in the potential window of -1 to $0 \mathrm{~V}$. Capacitances of $94.5 \%$ of the initial, at current densities of $10 \mathrm{~A} \mathrm{~g}^{-1}$ after 1000 cycles were
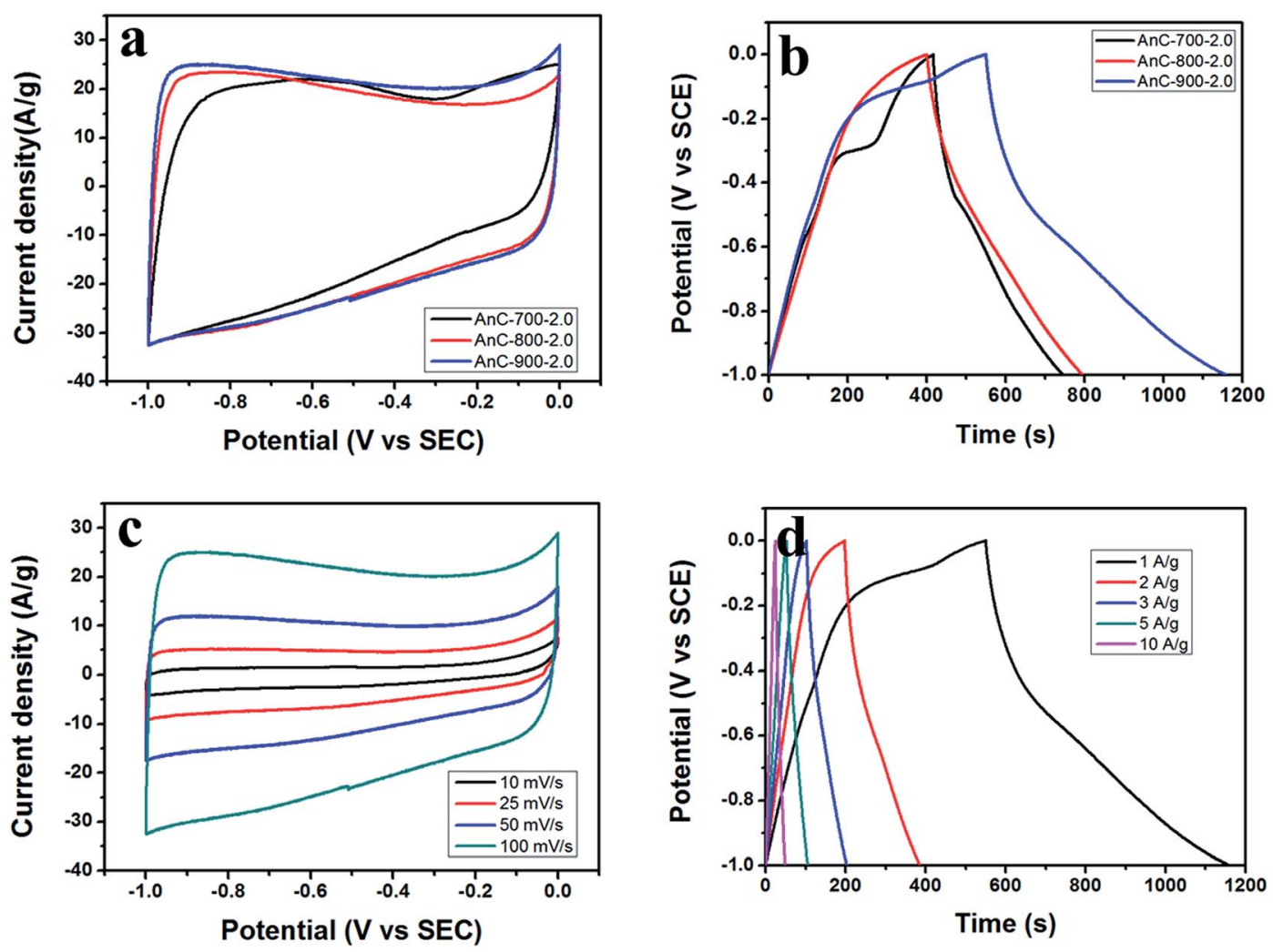

Fig. 6 (a) Cyclic voltammetry (CV) curves of AnC electrodes in $6 \mathrm{M} \mathrm{KOH}$ electrolyte at $100 \mathrm{mV} \mathrm{s}^{-1}$. (b) Galvanostatic charge-discharge (GCD) curves of AnC electrodes at current density of $1 \mathrm{~A} \mathrm{~g}^{-1}$. (c) CV curves of AnC-900-2.0 sample at various scan rate (10-100 mV s${ }^{-1}$ ). (d) GCD curves of AnC-900-2.0 sample at different current densities (1-10 $\left.\mathrm{A} \mathrm{g}^{-1}\right)$. 

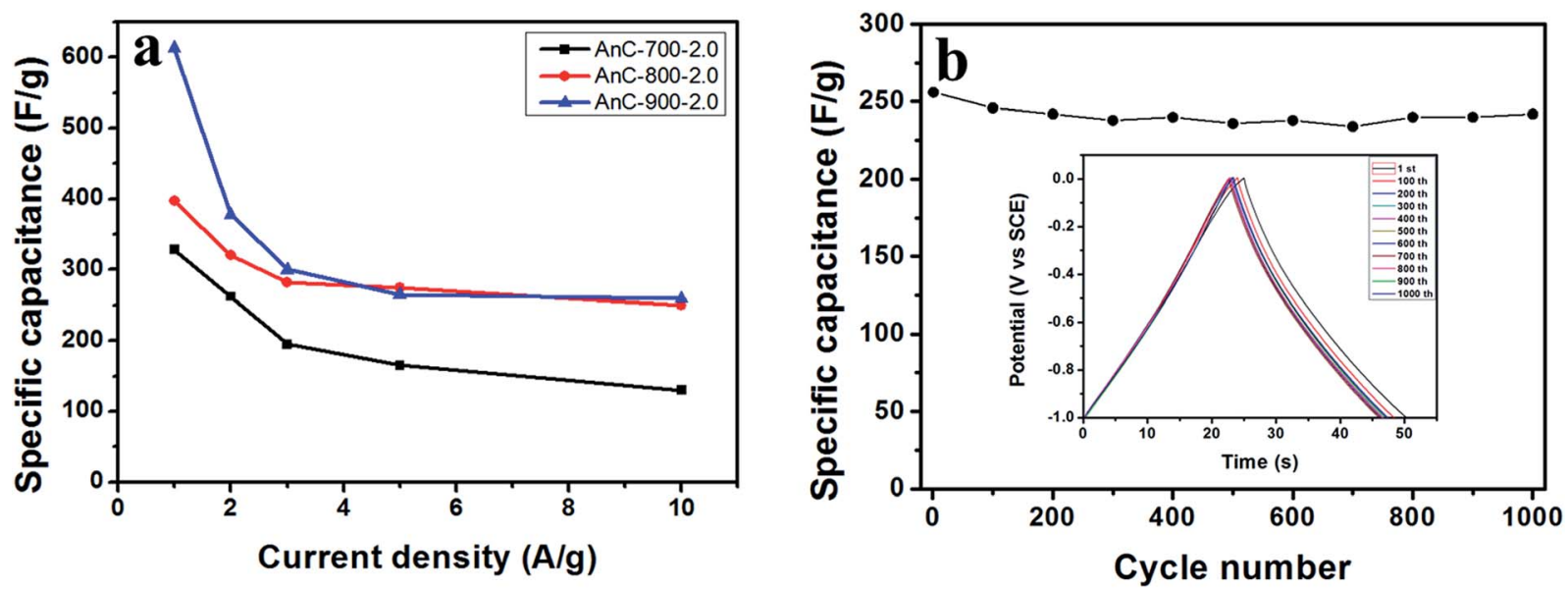

Fig. 7 (a) Rate capability of AnC samples. (b) Cyclic stability of AnC-900-2.0 at current density of 10 A g $^{-1}$ for 1000 cycles. Inset: galvanostatic charge-discharge of AnC-900-2.0.

obtained, indicating excellent capacitance retention (see Fig. 7b).

\subsection{Electrocatalytic performance in CE of DSSC}

The AnC samples can offer efficient charge/ion diffusion channels and electrocatalytic activity due to their porous nature, the moderate heteroatom doping level, the high charge polarisation of the nitrogen atom and the large size of the sulfur atom. Additionally, the lone-pair electrons of the doped heteroatom in the carbon matrix can serve as electron donors to boost the reduction of $\mathrm{Co}(\mathrm{bpy})_{3}{ }^{3+}$ (bpy $=2,2^{\prime}$-bipyridine) in DSSCs. Therefore, AnCs can be expected to be efficient CE alternatives to Pt catalysts. In this study, we demonstrate the synthesis of AnC materials for DSSC CEs. It was employed as representative $\mathrm{CE}$ material to evaluate the catalytic ability of
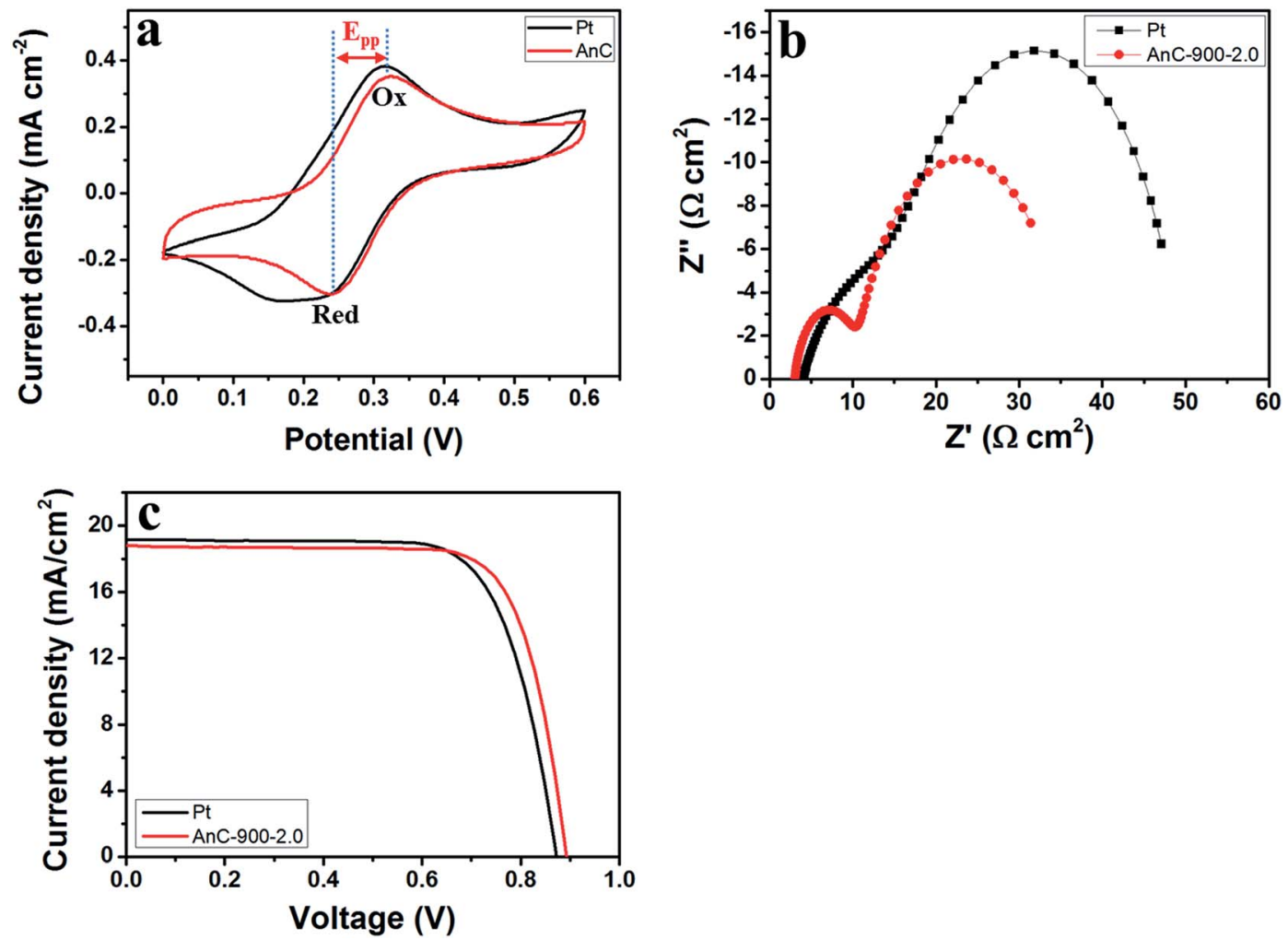

Fig. 8 (a) Cyclic voltammograms obtained at a scan rate of $10 \mathrm{mV} \mathrm{s}^{-1}$ for oxidation and reduction of the Co(bpy) ${ }_{3}^{2+/ 3+}$ redox couple using Pt and AnC-900-2.0 electrodes as the working electrodes, a Pt wire as the $\mathrm{CE}, \mathrm{Ag} / \mathrm{Ag}^{+}$as the reference electrode, and $0.1 \mathrm{M} \mathrm{LiClO}{ }_{4}$ as the supporting electrolyte. (b) Nyquist plots measured at $0 \vee$ from $1 \times 10^{6}$ to $0.1 \mathrm{~Hz}$ on symmetrical dummy cells with Pt and AnC-900-2.0 electrodes. (c) Current-voltage characteristics of the DSSCs with Pt and AnC-900-2.0 CEs. 
$\mathrm{Co}(\mathrm{bpy})_{3}{ }^{3+}$ reduction, and a Pt electrode was also measured for comparison. For use as the CE in a DSSC, AnC thin films were prepared on fluorine-doped $\mathrm{SnO}_{2}$ (FTO)/glass substrates by using an electrostatic-spray (e-spray) technique, ${ }^{7,20,22,23,25}$ and their fabrication procedure is described in detail in the (ESI $\dagger$ ). The CV curves of AnC-900-2.0 and Pt electrodes in the $\mathrm{Co}(\mathrm{bpy})_{3}{ }^{2+/ 3+}$ system with different scan rates are presented in Fig. 8a. A typical pair of oxidation and reduction peaks (Ox and Red, as denoted in Fig. 8a) is well resolved in the range of 0.0 to $0.6 \mathrm{~V}$. The peak-to-peak separation $\left(E_{\mathrm{pp}}\right)$ and the peak current are two important parameters for comparing catalytic activities of both CEs. A smaller $E_{\mathrm{pp}}$ and larger peak currents indicate higher catalytic performance. As shown in Fig. 8a, the $E_{\mathrm{pp}}$ and peak current of both electrodes are almost similar at $25 \mathrm{mV} \mathrm{s}^{-1}$ scan rate. Further indications of the higher electrocatalytic activity of AnC-900-2.0 come from the comparison of the $\mathrm{CV}$ curves of AnC-900-2.0 and Pt electrodes in the Co(bpy $)_{3}{ }^{2+/ 3+}$ system acquired at different scan rates $\left(25-200 \mathrm{mV} \mathrm{s}^{-1}\right)$ and are presented in Fig. S3a and b. $\uparrow$ The greater slopes of the linear dependence of the reduction and oxidation currents against the square root of potential and their currents (Fig. S3c and $d, \dagger$ respectively) observed for AnC-900-2.0 suggest its higher electrocatalytic activity towards the reduction of $\mathrm{Co}(\mathrm{bpy})_{3}{ }^{3+}$. To evaluate the electrocatalytic activity of the sample electrodes, electrochemical impedance spectroscopy (EIS) was carried out with symmetrical dummy cells by using two identical electrodes. As shown in Fig. 8b, Nyquist plots of both devices show two distinct semicircles in the high- and low-frequency regions. The impedance of CE commonly comprises the intrinsic series resistance $\left(R_{\mathrm{S}}\right)$, charge-transfer resistance $\left(R_{\mathrm{CT}}\right)$, and Nernst diffusion impedance $\left(Z_{\mathrm{W}}\right)$. The high-frequency intercept on the real axis $\left(Z^{\prime}\right)$ represents series resistance $\left(R_{\mathrm{S}}\right)$, which is mainly composed of contact resistance between AnC-900-2.0/FTO and Pt/FTO electrodes, and/or bulk electrolyte solution. The semicircles in the high-frequency region arise from the chargetransfer resistance $\left(R_{\mathrm{CT}}\right)$ at the CE/electrolyte interface. The Nernst diffusion impedance $\left(Z_{\mathrm{W}}\right)$ describes the diffusion of the redox couple between two electrodes. From Table $3, R_{\mathrm{S}}$ of Pt and AnC-900-2.0 are estimated to be 3.87 and $3.00 \Omega \mathrm{cm}^{2}$, respectively. $R_{\mathrm{CT}}$ of Pt and AnC-900-2.0 are estimated to be 14.71 and $7.56 \Omega \mathrm{cm}^{2}$, respectively. $R_{\mathrm{CT}}$ is the resistance at the counter electrode/electrolyte interface for $\mathrm{Co}(\mathrm{bpy})_{3}{ }^{3+}$ reduction, and the lower $R_{\mathrm{CT}}$ indicates higher electrocatalytic activity.

On the basis of the in-depth evaluation of the AnC-900-2.0, the electrocatalytic activity of the AnC-900-2.0-CE in actual organic DSSC devices was observed in the SM-315 porphyrin sensitizer-based DSSCs with the $\mathrm{Co}(\mathrm{bpy})_{3}{ }^{2+/ 3+}$ redox couple. ${ }^{55,56}$ Fig. 8c shows the current-voltage $(J-V)$ characteristics, and their photovoltaic parameters are summarised in Table 3. As can be seen, the Pt-based DSSC exhibited a short circuit current $\left(J_{\mathrm{SC}}\right)$ of $19.173 \mathrm{~mA} \mathrm{~cm}{ }^{-2}$, a $V_{\mathrm{OC}}$ of $872.269 \mathrm{mV}$, a $\mathrm{FF}$ of $73.11 \%$, and a PCE of $12.23 \%$. The DSSC with AnC-900-2.0 CE showed photovoltaic performance of a $J_{\mathrm{SC}}$ of $18.784 \mathrm{~mA} \mathrm{~cm}^{-2}$, a $V_{\mathrm{OC}}$ of $892.641 \mathrm{mV}$, an FF of $75.88 \%$, and a PCE of $12.72 \%$, respectively. These results indicate that AnC-900-2.0-based DSSC employing SM-315 as a superior organic sensitizer leads to a better power conversion efficiency (PCE) of $12.72 \%$ compared to that of a Ptbased DSSC (12.23\%), due to the large fill factor enhancement arising from better electrocatalytic ability. To the best of our knowledge, this obtained PCE of $12.72 \%$ is the highest value

Table 3 Photovoltaic performance of the DSSCs with AnC-900-2.0 and Pt

\begin{tabular}{|c|c|c|c|c|c|c|c|}
\hline $\mathrm{CE}$ & Dye/electrolyte & $\begin{array}{l}R_{\mathrm{S}} \\
\left(\Omega \mathrm{cm}^{2}\right)\end{array}$ & $\begin{array}{l}R_{\mathrm{CT}} \\
\left(\Omega \mathrm{cm}^{2}\right)\end{array}$ & $\begin{array}{l}J_{\mathrm{SC}} \\
\left(\mathrm{mA} \mathrm{cm}^{-2}\right)\end{array}$ & $V_{\mathrm{OC}}(\mathrm{mV})$ & $\mathrm{FF}(\%)$ & PCE (\%) \\
\hline Pt & SM-315/Co(bpy $)_{3}{ }^{2+/ 3+}$ & 3.87 & 14.71 & $19.17(18.79 \pm 0.33)$ & $872.27(882.02 \pm 13.57)$ & $73.11(72.38 \pm 0.98)$ & $12.23(11.99 \pm 0.21)$ \\
\hline
\end{tabular}
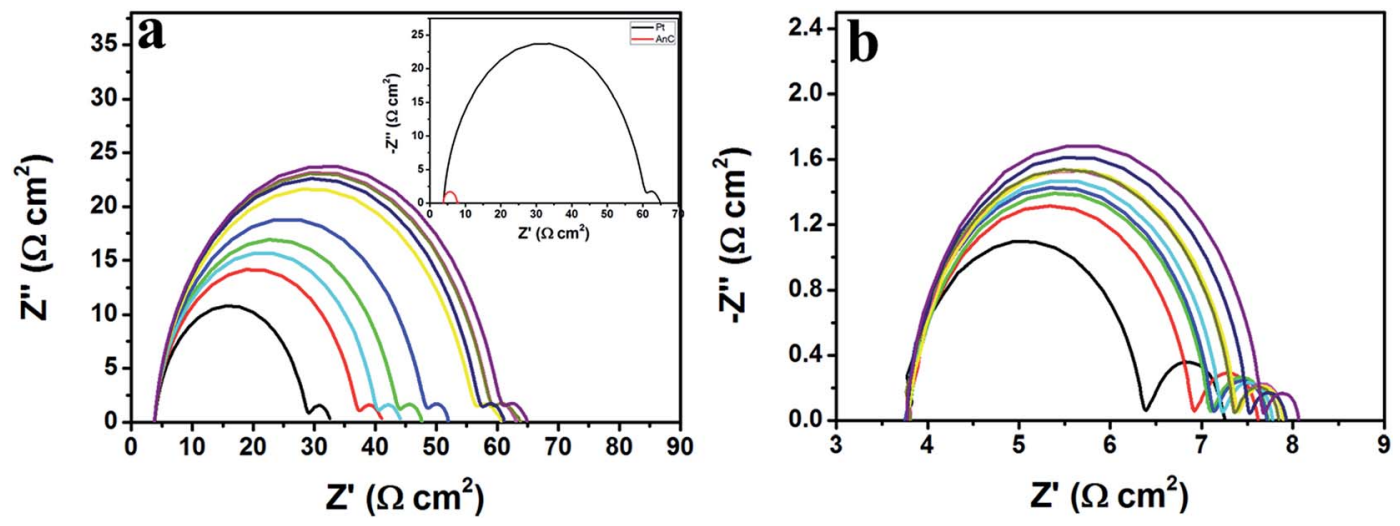

Fig. 9 Nyquist plots showing the electrochemical stability under cycling potential on dummy cells with Pt (a) and AnC-900-2.0 (b) electrodes in an acetonitrile solution of $\mathrm{Co}(\mathrm{bpy})_{3}{ }^{2+/ 3+}$. The sequence of measurements was as follows: 100 cycles $\times \mathrm{CV}$ scan (from $0 \mathrm{~V} \rightarrow 1 \mathrm{~V} \rightarrow-1 \mathrm{~V} \rightarrow 0 \mathrm{~V}$ $\rightarrow 1 \mathrm{~V}$; scan rate $50 \mathrm{mV} \mathrm{s}^{-1}$ ); $30 \mathrm{~s}$ relaxation at $0 \mathrm{~V}$; EIS measurements at $0 \mathrm{~V}$ from $1 \times 10^{6}$ to $0.1 \mathrm{~Hz}$. This sequence of electrochemical stability test was repeated 10 times. The inset is the EIS data of Pt and AnC-900-2.0 for after 10 cycles. 
reported for DSSCs based on carbon nanomaterials as counter electrode to date..$^{7,20,22,23,25}$

To evaluate the electrochemical stability of the CEs, dummy cells were first investigated with CV and then subjected to EIS cycles followed by additional CV measurements (Fig. 8a and b). The $R_{\mathrm{CT}}$ of the Pt was significantly increased from the first to the final cycle (Fig. 9a). On the other hand, the $R_{\mathrm{CT}}$ value of the AnC900-2.0 was slightly increased (Fig. 9b). As can be seen in Fig. 9a and $b$, despite cycling potentials, the semicircles in the lowfrequency region exhibited a similar shape to those in the plots of the AnC-900-2.0 and Pt electrodes. For example, these similar curves for the two electrodes indicate that the $\mathrm{Co}(\mathrm{bpy})_{3}{ }^{2+3+}$ redox couple is invariant with the surface conditions at the electrodes. However, the $R_{\mathrm{CT}}$ of the Pt electrode increased significantly compared to the AnC-900-2.0 electrode as the cycling potential was repeated. Thus, it is reasonable to conclude that the AnC-900-2.0 electrode in a $\mathrm{Co}(\mathrm{bpy})_{3}{ }^{2+/ 3+}$ medium has better electrochemical stability than does a Pt electrode.

\section{Conclusion}

In summary, anchovy-derived nitrogen and sulfur co-doped porous carbons were prepared by $\mathrm{KOH}$ activation and carbonization of the anchovy precursor. The high BET surface area with abundant mesopore and moderate heteroatom ( $\mathrm{N}$ and $\mathrm{S}$ ) doping levels resulted in an efficient electrode for highperformance supercapacitor with high capacitance, rate capability and long-term stability. In particular, the high mesopore volume within the carbon structure allowed more efficient electrolyte diffusion and charge accumulation when used as a supercapacitor electrode. Moreover, the porous texture and moderate heteroatom doping level could enhance the electrocatalytic ability on reduction of the $\mathrm{Co}(\mathrm{bpy})_{3}{ }^{2+/ 3+}$ redox couple in DSSCs. An AnC-900-2.0-based DSSC employing SM-315 as an organic sensitizer led to the better power conversion efficiency (PCE) of $12.72 \%$, which is to the best of our knowledge the highest value reported for DSSCs based on carbon nanomaterials as CEs, compared to that of a Pt-based DSSC (12.23\%), due to the large fill factor enhancement arising from better electrocatalytic ability. Thus, anchovy-derived nitrogen and sulfur co-doped porous carbons (AnCs) may provide new insights and practical methods for the development of low-cost and highly durable carbon-based electrodes in supercapacitors and DSSCs.

\section{Acknowledgements}

This work was supported by the National Research Foundation of Korea (NRF) grant funded by the Korean government (MSIP) through the Mid-career Researcher Program (2014R1A2A1A10051630), the Functional Districts of the Science Belt Support Program (2015K000287), Climate Change Program (2015M1A2A2056543) and the International Collaborative Energy Technology R\&D Program of the Korean Institute of Energy Technology Evaluation and Planning (KETEP) with a grant funded by the Ministry of Trade, Industry \& Energy, Republic of Korea (20148520011250).

\section{References}

1 A. S. Arico, P. Bruce, B. Scrosati, J.-M. Tarascon and W. van Schalkwijk, Nat. Mater., 2005, 4, 366-377.

2 L. Dai, D. W. Chang, J.-B. Baek and W. Lu, Small, 2012, 8, 1130-1166.

3 L. L. Zhang and X. S. Zhao, Chem. Soc. Rev., 2009, 38, 25202531.

4 Y. Zhai, Y. Dou, D. Zhao, P. F. Fulvio, R. T. Mayes and S. Dai, Adv. Mater., 2011, 23, 4828-4850.

5 K. H. An, W. S. Kim, Y. S. Park, J. M. Moon, D. J. Bae, S. C. Lim, Y. S. Lee and Y. H. Lee, Adv. Funct. Mater., 2001, 11, 387-392.

6 M. D. Stoller, S. Park, Y. Zhu, J. An and R. S. Ruoff, Nano Lett., 2008, 8, 3498-3502.

7 I.-Y. Jeon, M. J. Ju, J. Xu, H.-J. Choi, J.-M. Seo, M.-J. Kim, I. T. Choi, H. M. Kim, J. C. Kim, J.-J. Lee, H. K. Liu, H. K. Kim, S. Dou, L. Dai and J.-B. Baek, Adv. Funct. Mater., 2015, 25, 1170-1179.

8 D.-S. Yang, D. Bhattacharjya, S. Inamdar, J. Park and J.-S. Yu, J. Am. Chem. Soc., 2012, 134, 16127-16130.

9 E. Frackowiak, Phys. Chem. Chem. Phys., 2007, 9, 1774-1785. 10 Y. Wang, Y. Song and Y. Xia, Chem. Soc. Rev., 2016, 45, 59255950.

11 J. Yan, Q. Wang, T. Wei and Z. Fan, Adv. Energy Mater., 2014, 4, 1300816.

12 V. Etacheri, R. Marom, R. Elazari, G. Salitra and D. Aurbach, Energy Environ. Sci., 2011, 4, 3243-3262.

13 M. K. Debe, Nature, 2012, 486, 43-51.

14 B. O'Regan and M. Gratzel, Nature, 1991, 353, 737-740.

15 M. Gratzel, Nature, 2001, 414, 338-344.

16 G. Wang, L. Zhang and J. Zhang, Chem. Soc. Rev., 2012, 41, 797-828.

17 E. Frackowiak and F. Béguin, Carbon, 2001, 39, 937-950.

18 S. Bose, T. Kuila, A. K. Mishra, R. Rajasekar, N. H. Kim and J. H. Lee, J. Mater. Chem., 2012, 22, 767-784.

19 M. Grätzel, J. Photochem. Photobiol., C, 2003, 4, 145-153.

20 H. M. Kim, I.-Y. Jeon, I. T. Choi, S. H. Kang, S.-H. Shin, H. Y. Jeong, M. J. Ju, J.-B. Baek and H. K. Kim, J. Mater. Chem. A, 2016, 4, 9029-9037.

21 M. J. Ju, I.-Y. Jeon, H. M. Kim, J. I. Choi, S.-M. Jung, J.-M. Seo, I. T. Choi, S. H. Kang, H. S. Kim, M. J. Noh, J.-J. Lee, H. Y. Jeong, H. K. Kim, Y.-H. Kim and J.-B. Baek, Sci. Adv., 2016, 56, e1501459.

22 S.-M. Jung, I. T. Choi, K. Lim, J. Ko, J. C. Kim, J.-J. Lee, M. J. Ju, H. K. Kim and J.-B. Baek, Chem. Mater., 2014, 26, 3586-3591.

23 M. J. Ju, I. T. Choi, M. Zhong, K. Lim, J. Ko, J. Mohin, M. Lamson, T. Kowalewski, K. Matyjaszewski and H. K. Kim, J. Mater. Chem. A, 2015, 3, 4413-4419.

24 B. Lee, D. B. Buchholz and R. P. H. Chang, Energy Environ. Sci., 2012, 5, 6941-6952.

25 I.-Y. Jeon, H. M. Kim, I. T. Choi, K. Lim, J. Ko, J. C. Kim, H.-J. Choi, M. J. Ju, J.-J. Lee, H. K. Kim and J.-B. Baek, Nano Energy, 2015, 13, 336-345.

26 L.-F. Chen, X.-D. Zhang, H.-W. Liang, M. Kong, Q.-F. Guan, P. Chen, Z.-Y. Wu and S.-H. Yu, ACS Nano, 2012, 6, 7092-7102. 
27 L. Yang, S. Jiang, Y. Zhao, L. Zhu, S. Chen, X. Wang, Q. Wu, J. Ma, Y. Ma and Z. Hu, Angew. Chem., Int. Ed., 2011, 50, 7132-7135.

28 T. Wang, L.-X. Wang, D.-L. Wu, W. Xia and D.-Z. Jia, Sci. Rep., 2015, 5, 9591.

29 T. Panja, D. Bhattacharjya and J.-S. Yu, J. Mater. Chem. A, 2015, 3, 18001-18009.

$30 \mathrm{~J}$. Li, G. Zan and Q. Wu, RSC Adv., 2016, 6, 57464-57472.

31 W. Luo, B. Wang, C. G. Heron, M. J. Allen, J. Morre, C. S. Maier, W. F. Stickle and X. Ji, Nano Lett., 2014, 14, 2225-2229.

32 D. Geng, Y. Chen, Y. Chen, Y. Li, R. Li, X. Sun, S. Ye and S. Knights, Energy Environ. Sci., 2011, 4, 760-764.

33 J. Liang, Y. Jiao, M. Jaroniec and S. Z. Qiao, Angew. Chem., Int. Ed., 2012, 51, 11496-11500.

34 Z.-L. Wang, D. Xu, H.-G. Wang, Z. Wu and X.-B. Zhang, ACS Nano, 2013, 7, 2422-2430.

35 X. Wang, J. Wang, D. Wang, S. Dou, Z. Ma, J. Wu, L. Tao, A. Shen, C. Ouyang, Q. Liu and S. Wang, Chem. Commun., 2014, 50, 4839-4842.

36 D. Qu, M. Zheng, P. Du, Y. Zhou, L. Zhang, D. Li, H. Tan, Z. Zhao, Z. Xie and Z. Sun, Nanoscale, 2013, 5, 12272-12277.

37 J. Xu, G. Dong, C. Jin, M. Huang and L. Guan, ChemSusChem, 2013, 6, 493-499.

38 P. Guo, F. Xiao, Q. Liu, H. Liu, Y. Guo, J. R. Gong, S. Wang and Y. Liu, Sci. Rep., 2013, 3, 3499.

39 Y. Su, Y. Zhang, X. Zhuang, S. Li, D. Wu, F. Zhang and X. Feng, Carbon, 2013, 62, 296-301.

40 L. Li, E. Liu, J. Li, Y. Yang, H. Shen, Z. Huang, X. Xiang and W. Li, J. Power Sources, 2010, 195, 1516-1521.

41 M. Zhong, E. K. Kim, J. P. McGann, S.-E. Chun, J. F. Whitacre, M. Jaroniec, K. Matyjaszewski and T. Kowalewski, J. Am. Chem. Soc., 2012, 134, 14846-14857.
42 Y. Deng, Y. Xie, K. Zou and X. Ji, J. Mater. Chem. A, 2016, 4, 1144-1173.

43 C. Zhan, X. Yu, Q. Liang, W. Liu, Y. Wang, R. Lv, Z.-H. Huang and F. Kang, RSC Adv., 2016, 6, 89391-89396.

44 R.-J. Mo, Y. Zhao, M. Wu, H.-M. Xiao, S. Kuga, Y. Huang, J.-P. Li and S.-Y. Fu, RSC Adv., 2016, 6, 59333-59342.

45 A. Bello, N. Manyala, F. Barzegar, A. A. Khaleed, D. Y. Momodu and J. K. Dangbegnon, RSC Adv., 2016, 6, 1800-1809.

46 J. Wang and Q. Liu, RSC Adv., 2015, 5, 4396-4403.

47 M. Zhi, F. Yang, F. Meng, M. Li, A. Manivannan and N. Wu, ACS Sustainable Chem. Eng., 2014, 2, 1592-1598.

48 D. A. Siriskar, G. D. Khedkar and D. Lior, J. Food Sci. Technol., 2013, 50, 1172-1178.

49 G. Leofanti, M. Padovan, G. Tozzola and B. Venturelli, Catal. Today, 1998, 41, 207-219.

50 J. Zeng, Q. Cao, B. Jing and X. Peng, RSC Adv., 2016, 6, 1532015326.

51 S. Gao, K. Geng, H. Liu, X. Wei, M. Zhang, P. Wang and J. Wang, Energy Environ. Sci., 2015, 8, 221-229.

52 L. Hao, X. Li and L. Zhi, Adv. Mater., 2013, 25, 3899-3904.

53 K. László, E. Tombácz and K. Josepovits, Carbon, 2001, 39, 1217-1228.

54 M. Y. Song, H. Y. Park, D.-S. Yang, D. Bhattacharjya and J.-S. Yu, ChemSusChem, 2014, 7, 1755-1763.

55 S. Mathew, A. Yella, P. Gao, R. Humphry-Baker, F. E. CurchodBasile, N. Ashari-Astani, I. Tavernelli, U. Rothlisberger, K. NazeeruddinMd and M. Grätzel, Nat. Chem., 2014, 6, 242-247.

56 S. H. Kang, M. J. Jeong, Y. K. Eom, I. T. Choi, S. M. Kwon, Y. Yoo, J. Kim, J. Kwon, J. H. Park and H. K. Kim, Adv. Energy Mater., 2017, 7, 1602117. 